\title{
Experimental study of cold inflow and its effect on draft of a chimney
}

\author{
C. Chi-Ming Chu, R. Kwok-How Chu \& M. M. Rahman \\ Chemical Engineering Programme, School of Engineering and \\ Information Technology, Universiti Malaysia Sabah, Malaysia
}

\begin{abstract}
This paper aims to study the cold air inflow into a natural draft air cooled heat exchanger chimney. In total, seven configurations of experiments were carried out in the prototype natural draft air-cooled heat exchanger model for two different supplied heat loads at approximately $0.75 \mathrm{~kW}$ to $1.25 \mathrm{~kW}$ to determine the effects of wire mesh screen in the chimney performance. Temperature and velocity were measured for the configurations and heat loads. It was found that the Top-only, Top-and-Middle, and Middle-only installations were able to maintain draft velocities to within $3.0 \%$ of the control experiment draft velocity, in spite of the resistance of the mesh. It was also found that configurations utilising mesh at the bottom had experienced a drop in draft velocity by up to $50 \%$ from the Control. The smoke flow visualisation tests clearly proved that cold air inflow phenomenon exist, and can be countered with the installation of wire mesh at the top of the model.

Keywords: cold inflow, natural draft, heat exchanger, smoke visualisation, wire mesh.
\end{abstract}

\section{Introduction}

In the natural draft air cooled heat exchanger (NDACHX) or cooling tower, the hot air continuously flows in the upward direction and the cold air enters from bottom. The airflow is due solely to local buoyancy differences caused by the presence of temperature difference between process side and ambient. However, in the forced convection process, a fan is placed either at the bottom or above the tube bundle to increase airflow rate to remove waste heat. In certain appliances, natural draft air cooled heat exchanger has the advantage in terms of operational 
safety and reliability (Chu [1]). The utilisation of natural buoyancy of hot air to generate draft which cools the tube bundle means that energy and water can be saved in the process, and this is generally useful in countries where energy and water resources are scarce, for example the Middle East and South Africa.

Whether the field is cooling tower or solar chimney or vertical channel cooling, a commonly acknowledged problem is that they experience unstable flow with breezes leading to undesirable downdraft (Costola and Etheridge [2]; Bouchair [3]; Kröger [4]; Baer et al. [5]). Under laboratory conditions, one of the earliest studies of cold inflow was undertaken by Jörg and Scorer [6], who developed a correlation for predicting the extent of penetration for small density difference of gases. Fisher and Torrance [7] quantified that cold inflow affects heat transfer performance by 4 per cent on heat exchanging devices for electronic applications. Modi and Torrance [8] performed numerical and experimental investigations of cold inflow phenomenon in a channel flow and laid down a criterion of Froude number at below 1.4-2.0 and Reynolds number exceeding 3000 for the onset of cold inflow. More recently, research on chimney effect of natural convection was widely carried out for vertical channels of various configurations and optimization of standard configurations with applications mainly in electronics industry (Nishino et al. [9]; Auletta and Manca [10]; Auletta et al. [11], Manca et al. [12] and Thrasher et al. [13]) which are of smaller dimensions than heat exchanging equipment in process industry. Their experiments typically aimed at optimizing the configurations for more efficient heat transfer, usually by means of geometrical manipulation. Auletta et al. [11] performed experiments on a chimney with insulated extension and concluded that cold inflow was responsible for the dip in wall temperature near the exit.

Andreozzi et al. [14] were able to simulate numerically the experimental results of Auletta et al. [11] with the indication of cold inflow by a dip in the wall temperature near the outlet of particular interest in this study, which follows from the cold inflow study reported in Chu et al. [15]. They contended that the geometry studied in their numerical investigation was important in different technical fields, such as in electronic cooling and in building and houses' solar components, as indicated in Costola and Etheridge [2] and Bouchair [3].

In the work reported here, a chimney model was installed with wire mesh screens at three different positions: top, middle and bottom. Seven combinations of the positions were investigated for draft rate and exit temperature at fixed heat loads by means of electrical coil.

\section{Experimental implementation}

\subsection{The experimental model}

The model has an inlet diameter of $0.10 \mathrm{~m}$, an outlet diameter of $0.31 \mathrm{~m}$ and total length of $1.10 \mathrm{~m}$ as shown in the Figure 1. The heater is installed with its top at a distance of $0.35 \mathrm{~m}$ from the outlet. 


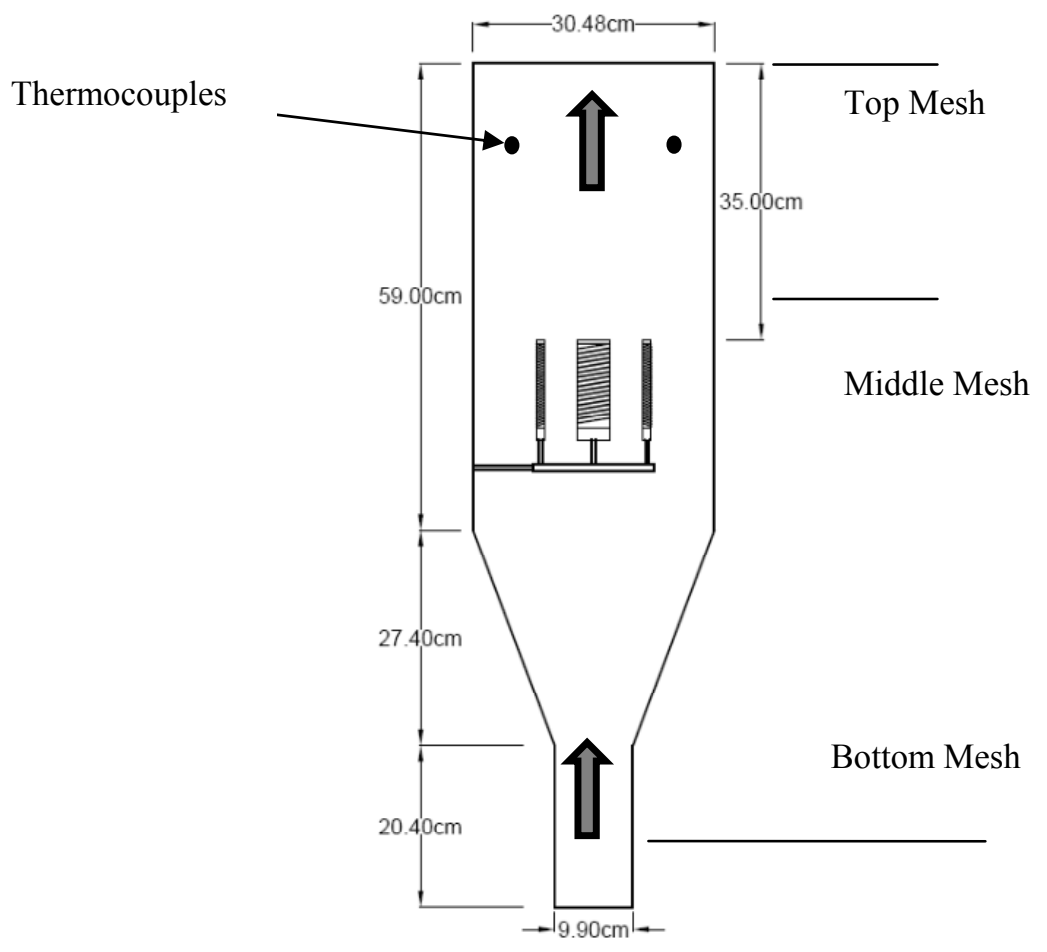

Figure 1: Dimensions of the NDACHE model.

The heater consists of three electrical heating elements wrapped around standing ceramic bars, equally spaced from each other in a circle, to simulate the pipe bundles channelling the hot side fluid in a natural draft heat exchanger. In this study, the AC voltages were set in such a way that achieved a heating supply at approximately $0.75 \mathrm{~kW}$ and $1.25 \mathrm{~kW}$. The heating elements would heat the air in the chimney, causing it to rise. The rising hot air would be replaced with cold air form the bottom of the assembly, thus generating a draft.

The prototype was modified by adding stainless steel wire mesh at the top (completely covers the exit of the model), middle (mesh placed $4-5 \mathrm{~cm}$ above heating elements), below (mesh placed $7-8 \mathrm{~cm}$ from the inlet), or combinations of the placements.

Two type-K thermocouples were used in the chimney chamber at $15 \mathrm{~cm}$ below from the top wire mesh and $5 \mathrm{~cm}$ from the side wall. A vane anemometer of brand Airflow LC430VA, with a resolution $\pm 0.01 \mathrm{~ms}^{-1}$ was employed to measure the inlet air velocity. 


\subsection{Data collection procedure}

\subsubsection{Draft investigation}

Stainless steel meshes were installed at different locations of the chimney according to the various configurations. The power supply to the prototype and data logger was turned on. Voltage regulator was set and actual voltage and current were measured and recorded. The prototype was allowed to stabilise for a minimum of 10 minutes, by waiting until the data logger plot showed a steady state temperature reading. Once the system had stabilised, a vane anemometer was placed at the inlet of the prototype for 1 minute to allow for the rotor to pick up speed. Airflow velocity reading was taken according to this procedure: 5 points were taken at 3-minute intervals, where each point consisted of 3 readings at 30 -second intervals. Altogether it took about 23 minutes per velocity reading.

The experiment was repeated for voltages of $75 \mathrm{~V}$, and $100 \mathrm{~V}$, for different configurations as shown in the Table 1.

Table 1: Configurations for experiment on NDACHE model.

\begin{tabular}{|c|c|c|c|c|}
\hline Configuration & Code & $\begin{array}{c}\text { Mesh at the Top } \\
\text { of the Prototype } \\
\text { Model }\end{array}$ & $\begin{array}{c}\text { Mesh at the } \\
\text { Top of the } \\
\text { Electric heater }\end{array}$ & $\begin{array}{c}\text { Mesh at the } \\
\text { Bottom of the } \\
\text { Electric Heater }\end{array}$ \\
\hline 1 & T & Yes & No & No \\
\hline 2 & TM & Yes & Yes & No \\
\hline 3 & M & No & Yes & No \\
\hline 4 & TB & Yes & No & Yes \\
\hline 5 & TMB & Yes & Yes & Yes \\
\hline 6 & MB & No & Yes & Yes \\
\hline 7 & B & No & No & Yes \\
\hline 8 & C & No & No & No \\
\hline
\end{tabular}

\subsubsection{Flow pattern investigation}

An area with adequate lighting, proper ventilation, and power supply was selected with the model and video camera in position. The camera was placed at the same level of the prototype outlet. 2 pieces of black manila card was placed behind the prototype as background. The prototype was then turned on for different configurations and heat loads. Smoke was introduced at each configuration from the side and also from the bottom of the prototype. The flow pattern was photographed as well as videoed.

\section{Results and discussion}

\subsection{Analysis of the draft measurements}

Visual inspection of Tables 2 to 5 shows the measured velocity and temperature following nearly the same pattern between configurations in any experimental 
session whether it was at $0.75 \mathrm{~kW}$ or at $1.25 \mathrm{~kW}$ supply heat load supply. For example, Middle-only (M) and Top-and-Middle (TM) velocities were always higher than Control (C) while Bottom-only(B) was always the configuration with the lowest velocity. This is reassuring for comparison purpose so that within the same set of data the comparison carried between configurations out is acceptable. Minor variation in data is expected if carried out at different occasions.

Table 2: $\quad$ Measured entrance air velocity and average temperatures in the 0.3048-m Dia. Model for average heat load $0.75 \mathrm{~kW}(75 \mathrm{~V}, 9.5 \mathrm{~A})$.

\begin{tabular}{|c|c|c|c|c|c|c|c|c|}
\hline \multirow{2}{*}{$\begin{array}{c}\text { Air Inlet } \\
\text { Velocity (ms }\end{array} \mathbf{~}^{-1}$ ) } \\
\cline { 2 - 10 } & 1 & 2 & 3 & 4 & 5 & 6 & 7 & 8 \\
\cline { 2 - 10 } & $\mathrm{T}$ & $\mathrm{TM}$ & $\mathrm{M}$ & $\mathrm{TB}$ & $\mathrm{TMB}$ & $\mathrm{MB}$ & $\mathrm{B}$ & $\mathrm{C}$ \\
\hline Average & 0.97 & 0.99 & 0.96 & 0.6 & 0.65 & 0.6 & 0.49 & 0.96 \\
\hline $\begin{array}{c}\text { Standard } \\
\text { Deviation }\end{array}$ & 0.02 & 0.02 & 0.02 & 0.03 & 0.02 & 0.02 & 0.02 & 0.02 \\
\hline Maximum & 0.99 & 1.02 & 0.98 & 0.66 & 0.67 & 0.63 & 0.52 & 0.99 \\
\hline Minimum & 0.93 & 0.96 & 0.93 & 0.56 & 0.61 & 0.56 & 0.46 & 0.93 \\
\hline RANK & 2 & 1 & 4 & 7 & 5 & 6 & 8 & 3 \\
\hline Average Temperature $\left({ }^{\circ} \mathrm{C}\right)$ & \multicolumn{7}{|c|}{} & \multicolumn{7}{|c|}{} \\
\hline Point 1 & 95.0 & 81.2 & 56.8 & 118.5 & 111.3 & 70.2 & 82.4 & 75.1 \\
\hline Point 2 & 94.5 & 79.9 & 62.0 & 119.2 & 111.3 & 71.3 & 87.5 & 74.4 \\
\hline Ambient & 27.0 & 24.4 & 24.7 & 29.7 & 20.9 & 23.1 & 29.9 & 21.9 \\
\hline RANK & 3 & 5 & 8 & 1 & 2 & 7 & 4 & 6 \\
\hline
\end{tabular}

Table 3: $\quad$ Measured entrance air velocity and average temperatures in the $0.3048-\mathrm{m}$ Dia. Model for average heat load $1.25 \mathrm{~kW}$ $(100 \mathrm{~V}, 12.5 \mathrm{~A})$.

\begin{tabular}{|c|c|c|c|c|c|c|c|c|}
\hline \multirow{3}{*}{$\begin{array}{l}\text { Air Inlet Velocity } \\
\qquad\left(\mathrm{ms}^{-1}\right)\end{array}$} & \multicolumn{8}{|c|}{ Configuration } \\
\hline & 1 & 2 & 3 & 4 & 5 & 6 & 7 & 8 \\
\hline & $\mathrm{T}$ & $\mathrm{TM}$ & $\mathrm{M}$ & $\mathrm{TB}$ & TMB & $\mathrm{MB}$ & $\mathrm{B}$ & $\mathrm{C}$ \\
\hline Average Velocity & 1.11 & 1.17 & 1.18 & 0.74 & 0.77 & 0.77 & 0.68 & 1.15 \\
\hline $\begin{array}{c}\text { Standard } \\
\text { Deviation } \\
\end{array}$ & 0.03 & 0.02 & 0.04 & 0.03 & 0.02 & 0.02 & 0.03 & 0.02 \\
\hline $\begin{array}{l}\text { Maximum } \\
\text { Velocity }\end{array}$ & 1.15 & 1.2 & 1.23 & 0.81 & 0.8 & 0.8 & 0.75 & 1.19 \\
\hline $\begin{array}{l}\text { Minimum } \\
\text { Velocity }\end{array}$ & 1.06 & 1.13 & 1.12 & 0.7 & 0.74 & 0.73 & 0.64 & 1.12 \\
\hline RANK & 4 & 2 & 1 & 7 & 5 & 6 & 8 & 3 \\
\hline \multicolumn{9}{|c|}{ Average Temperature $\left({ }^{\circ} \mathrm{C}\right)$} \\
\hline Point 1 & 128 & 105 & 83.9 & 157 & 144 & 110 & 111 & 89 \\
\hline Point 2 & 125 & 105 & 84.4 & 160 & 150 & 116 & 118 & 94 \\
\hline Ambient & 29 & 24.5 & 26.6 & 30 & 22 & 23 & 29.9 & 26 \\
\hline RANK & 3 & 6 & 8 & 1 & 2 & 5 & 4 & 7 \\
\hline
\end{tabular}


78 Advanced Computational Methods and Experiments in Heat Transfer XII

Table 4: $\quad$ Heat balance at $1.25 \mathrm{~kW}\left(\right.$ Spec. Heat $\left.=1000 \mathrm{Jkg}^{-1} \mathrm{~K}^{-1}\right)$.

\begin{tabular}{|l|c|c|c|c|c|c|c|c|}
\hline \multirow{3}{*}{ Parameter } & \multicolumn{7}{|c|}{ Configuration } \\
\cline { 2 - 10 } & 1 & 2 & 3 & 4 & 5 & 6 & 7 & 8 \\
\cline { 2 - 10 } & $\mathrm{T}$ & $\mathrm{TM}$ & $\mathrm{M}$ & $\mathrm{TB}$ & $\mathrm{TMB}$ & $\mathrm{MB}$ & $\mathrm{B}$ & $\mathrm{C}$ \\
\hline $\begin{array}{l}\text { Flowrate } \\
\left(\times 10^{3} \mathrm{~m}^{3} \mathrm{~s}^{-1}\right)\end{array}$ & 8.7 & 9.2 & 9.3 & 5.8 & 6.1 & 6.1 & 5.3 & 9.0 \\
\hline $\begin{array}{l}\text { Inlet } \\
\begin{array}{l}\text { Density } \\
\left(\mathrm{kgm}^{-3}\right)\end{array}\end{array}$ & 1.23 & 1.24 & 1.23 & 1.23 & 1.25 & 1.24 & 1.23 & 1.24 \\
\hline $\begin{array}{l}\text { Temp. Rise } \\
(\mathrm{K})\end{array}$ & 97 & 80 & 58 & 129 & 126 & 89 & 85 & 65 \\
\hline $\begin{array}{l}\text { Heat gain } \\
(\mathrm{W})\end{array}$ & 1034 & 917 & 658 & 912 & 955 & 674 & 552 & 731 \\
\hline Diff. (\%) & -17.3 & -26.6 & -47.4 & -27.0 & -23.6 & -46.1 & -55.9 & -41.5 \\
\hline RANK & 1 & 2 & 7 & 4 & 3 & 6 & 8 & 5 \\
\hline
\end{tabular}

Table 5: $\quad$ Heat balance at $0.75 \mathrm{~kW}\left(\right.$ Spec. Heat $\left.=1000 \mathrm{Jkg}^{-1} \mathrm{~K}^{-1}\right)$.

\begin{tabular}{|l|c|c|c|c|c|c|c|c|}
\hline \multirow{3}{*}{ Parameter } & \multicolumn{7}{|c|}{ Configuration } \\
\cline { 2 - 10 } & 1 & 2 & 3 & 4 & 5 & 6 & 7 & 8 \\
\cline { 2 - 10 } & $\mathrm{T}$ & $\mathrm{TM}$ & $\mathrm{M}$ & $\mathrm{TB}$ & $\mathrm{TMB}$ & $\mathrm{MB}$ & $\mathrm{B}$ & $\mathrm{C}$ \\
\hline $\begin{array}{l}\text { Flowrate } \\
\left(\times 10^{3} \mathrm{~m}^{3} \mathrm{~s}^{-1}\right)\end{array}$ & 7.6 & 7.8 & 7.6 & 4.7 & 5.2 & 4.7 & 3.8 & 7.6 \\
\hline $\begin{array}{l}\text { Inlet Density } \\
\left(\mathrm{kgm}^{-3}\right)\end{array}$ & 1.23 & 1.24 & 1.24 & 1.23 & 1.25 & 1.24 & 1.23 & 1.24 \\
\hline $\begin{array}{l}\text { Temp. Rise } \\
(\mathrm{K})\end{array}$ & 68 & 56 & 35 & 89 & 90 & 48 & 55 & 53 \\
\hline $\begin{array}{l}\text { Heat gain } \\
(\mathrm{W})\end{array}$ & 635 & 544 & 325 & 513 & 581 & 281 & 258 & 500 \\
\hline Diff. (\%) & -15.3 & 27.5 & -56.7 & -31.6 & -22.5 & -62.5 & -65.5 & -33.4 \\
\hline RANK & 1 & 3 & 6 & 4 & 2 & 7 & 8 & 5 \\
\hline
\end{tabular}

The experimental results from prototype NDACHE model showed that inlet air velocity for $0.75 \mathrm{~kW}$ and $1.25 \mathrm{~kW}$ heat load were almost identical for Configurations T, TM, M and C. For other Configurations TB, TMB and MB, the inlet air velocity for both heat loads were two-thirds $(2 / 3)$ of the inlet air velocity measured in Configurations T, TM, M and $\mathrm{C}$ as shown in Tables 2 and 3 . From the velocity reading in the prototype NDACHE model, it was found that in both heat loads the wire mesh at the middle or top of the model did not affect entrance air velocity but wire mesh at the bottom of the heating system could cause up to 50 per cent less inlet air velocity in the system. Therefore in the prototype model, the wire mesh at the middle and at the top of the chimney had no significant effect on inlet air velocity whereas the wire mesh below the electric heater had significantly reduced the inlet air velocity. 
Therefore, the wire mesh at the bottom of the electric heater disturbed the suction flow that resulted in preferentially drawing cold air from the top, lowering the buoyancy hence the pumping power, and resulting in low inlet air velocity. The B-configuration had an inlet velocity that was lower than the TB configuration's by 9 per cent and yet the latter had one more wire mesh screen. Among configurations, the maximum measured chimney outlet temperatures were observed in Configuration TB for both $0.75 \mathrm{~kW}$ and $1.25 \mathrm{~kW}$ heat loads. Similar draft enhancements could be said of MB and TMB configurations.

For both heat load settings, the best wire mesh Configuration which produces the highest draft velocity is found among Configurations 1 to 3 . Compared to the control experiment (no mesh), the pattern remains that notwithstanding the wire mesh installed, the velocity was not reduced but rather were at least equal to that of Control (C).

\subsection{Analysis of heat balance}

The minimum measured chimney outlet temperatures were observed in Configuration 4, where the wire mesh was fixed at the middle of the system as shown in Tables 4 and 5. The wire mesh near to the electric heater received heat energy from heater due to radiation and also reduces the cold air inflow therefore chimney outlet temperature was low compared to other configurations.

For the $1.25 \mathrm{~kW}$ setting, the maximum heat apparently absorbed by air was achieved by the Top-only (T) Configuration, at $1034 \mathrm{~W}$, whereas the least heat apparently absorbed by air was achieved by the Bottom-only (B) Configuration, at $552 \mathrm{~W}$. This pattern was repeated for the $0.75 \mathrm{~kW}$ setting. The heat balance exercise is useful in determining if one configuration suffers cold inflow more than the other so that the performance of a NDACHX can be realistically assessed. Compared to Fisher and Torrance's [7] shortfall of measured heat transfer rate from the ideal theoretical value by 4 per cent in their heat sink fitted with a chimney, the C-configuration for heat load settings of $0.75 \mathrm{~kW}$ and 1.25 $\mathrm{kW}$ showed deficiency in heat transfer from the ideal electrical heat loads by -33 per cent and -42 per cent respectively. It is worth noticing that the TB configuration achieved the highest outlet temperature reading but the draft was about that of MB-configuration, which had a lower outlet temperature reading. This leads to the corollary that a higher draft was achieved not by a higher outlet temperature or better heat balance, but by the arrangement of wire mesh in the chimney itself.

\subsection{Analysis of flow visualization}

A smoke test was conducted in the prototype NDACHE model to determine the effect of wire mesh on cold air inflow or flow reversal. Smoke was charged into the prototype NDACHE model at the bottom and at the outlet. It was observed that there was some flow from the outside to the inside when there was no wire mesh (C) or wire meshes at the bottom and the middle of the system (MB) as illustrated in Figures 2 and 3. When the wire meshes were placed at the middle 


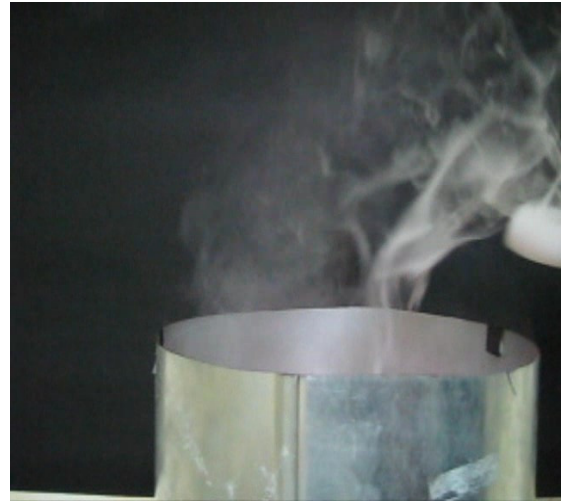

Figure 2: Smoke test in the NDACHX model for no wire mesh.

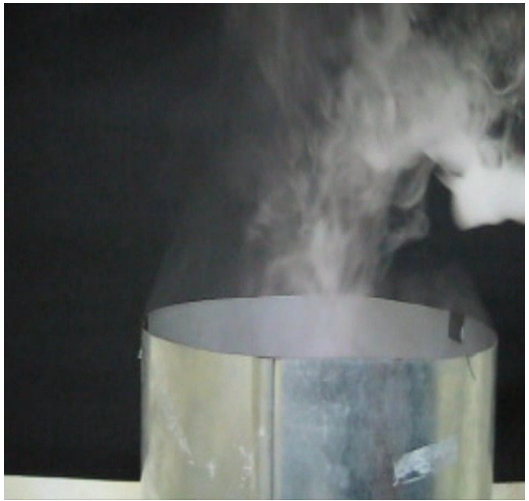

Smoke test in the NDACHX model with wire meshes at the middle and bottom.

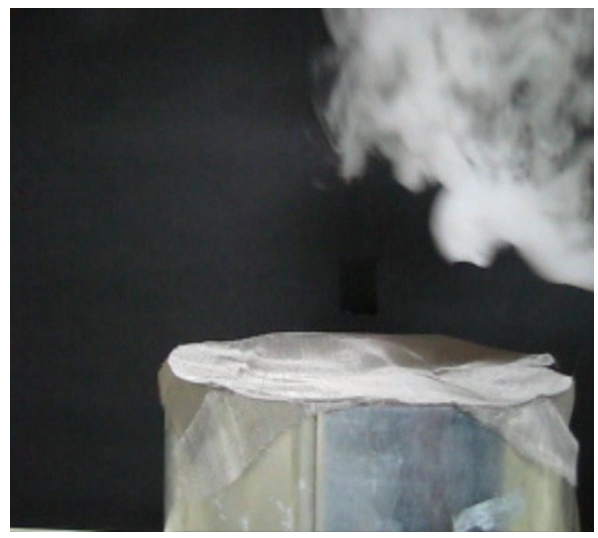

Figure 4: Smoke test in the NDACHX E model for wire meshes at the middle and top.

and top of the chimney (TM) the smoke gently flowed in an upward direction which showed that wire meshes were successful in blocking cold air inflow or flow reversal (Figure 4).

Therefore, placing wire meshes at the top of the chimney helped to restore air velocity and buoyancy by eliminating or reducing the effect of entrainment air, cold air inflow, or flow reversal, resulting in increased draft or convection heat transfer rate. The wire meshes in the chimney increased flow turbulence that caused more convectional heat transfer from electric heater to air, resulting in higher chimney outlet temperature and draft. It was found earlier that chimney with wire meshes at the top or middle significantly restored the entrance air velocity. 
The smoke flow visualisation vindicates Auletta et al. [11] experimental data and Andreozzi et al. [14] simulation of the same apparatus that there was a dip in the wall temperature toward the chimney top exit, and which they concluded was due to cold inflow or flow reversal.

\section{Conclusions}

There was evidence that cold inflow was present without any wire mesh or added resistance to the chimney, as shown by configuration $\mathrm{C}$.

The installation of wire mesh must be done at the right locations to reduce cold air inflow into a chimney. Wire mesh configurations of Top-only, Middleonly, and Top-and-Middle showed favourable results, in either enhancing or maintaining draft velocity at Control value to within 3 per cent, in spite of the resistance in airflow caused by the wire mesh. It can be concluded from the outlet temperature readings that the cold inflow into the chimney has been reduced by installing wire mesh at the Top-only, Middle-only and Top-andMiddle positions.

The poorest natural convection draft at the inlet was found with configuration Bottom-only showing that cold inflow was most detrimental with corresponding low outlet temperature measured.

The highest outlet temperature was measured with Top-and-Bottom configuration and the lowest outlet temperature with Middle-only for both heat loads. However, the highest temperature did not secure the highest draft.

Smoke visualisation tests have shown that

(i) Cold inflow exists at the top of the chimney and is prominent in Configurations with mesh at the bottom as well as without any mesh.

(ii) Addition of mesh at the top of the chimney can prevent cold inflow from happening.

(iii) The entry point of cold air at the outlet of the prototype is at the middle of the circular cross sectional area.

These results proved that the wire mesh installation could prevent cold inflow into a chimney, and that installation of mesh at the bottom (inlet) is not beneficial.

\section{References}

[1] Chu, C.M., A Preliminary Method for Estimating the Effective Plume Chimney Height above a Forced Draft Air-cooled Heat Exchanger operating under natural Convection", Heat Transfer Engineering, Taylor \& Francis, USA, Vol. 23, No. 3, pp-3-12, 2002.

[2] Costola, D. and Etheridge, D.W., Unsteady natural ventilation at model scale - flow reversal and discharge coefficients of a short stack and an orifice", Building and Environment. 43: 1491-1506, 2008. 
[3] Bouchair, A., Solar chimney for promoting cooling ventilation in southern Algeria, Building Service Engineering, Research and Technology, 15, (2), pp. 81-93, 1994.

[4] Kröger, D.G., Air-cooled heat exchangers and cooling towers, PennWell Books, Tulsa Oklahoma, 2004.

[5] Baer, E., Ernst, G. and Wurz, D., Effect of wind on the flow in the chimney of a Natural Draft Cooling Tower, VGB Kraftwerkstechnik,Vol. 60, No. 11, pp. 875-881, 1980.

[6] Jörg, O. and Scorer, R.S., An experimental study of cold inflow into chimneys, Atmospheric Environment, Vol. 1, No 6, pp. 645-646, Elsevier Ltd, 1967.

[7] Fisher, T.S. and Torrance, K.E., Experiments on chimney-enhanced free convection, Journal of Heat Transfer, ASME, 121, pp. 603-609, 1999.

[8] Modi, V. and Torrance, K.E., Experimental and Numerical Studies of Cold Inflow at the Exit of Buoyant Channel Flows, Journal of Heat Transfer, ASME, N.Y., Vol. 109, Issue 2, pp. 392-399, 1987.

[9] Nishino, Y., Ishizuka, M. and Nagakawa, S., Estimation of the optimum dimensions of a vertical channel model for natural air cooling in electronic equipment, Proceedings of the ASME 2009 InterPACK Conference, San Francisco, California, USA, July 19-23, IPACK2009, Paper No InterPACK2009-89103, 6 pages, 2009.

[10] Auletta, A. and Manca, O., Heat and fluid flow resulting from the chimney effect in a symmetrically heated vertical channel with adiabatic extensions, International Journal of Thermal Sciences, Elsevier, 41, pp. 1101-1111, 2002.

[11] Auletta, A., Manca, O., Morrone, B. and Nasoe, V. Heat transfer enhancement by the chimney effect in a vertical isoflux channel, International Journal of Heat and Mass Transfer, Elsevier, 44, pp. 4345-4357, 2001.

[12] Manca, O., Musto, M. and Naso, V., Flow visualization and air temperature measurements in symmetrically heated vertical channels with adiabatic extensions, American Society of Mechanical Engineers, Heat Transfer Division, (Publication) HTD, Volume 372, Issue 1, Pages 123-134, 2002.

[13] Thrasher, W.W., Fisher, T.S. and Torrance, K.E., Experiments on chimneyenhanced free convection from pin-fin heat sink, Journal of Electronic Packaging, Vol. 122, pp. 350-5, 2000.

[14] Andreozzi, A., Buonomo B. and Manca O., Thermal management of a symmetrically heated channel-chimney system. International Journal of Thermal Sciences 48 (3): 475-487, 2009.

[15] Chu C. M., Md. M. Rahman and S. Kumaresan, Effect of Cold Inflow on Chimney Height of Natural Draft Cooling Towers, Accepted to be published in Nuclear Engineering and Design, ISSN: 00295493, CODEN: NEDEA, DOI: 10.1016/j.nucengdes.2011.08.046, Elsevier, 2011. 